\title{
A FAST METHOD TO PREDICT THE COOLING TIME OF WAX FOR INVESTMENT CASTING PROCEDURE
}

\author{
Bogdan Valentan*; Ana Pilipovic**; Tomaz Brajlih*; Peter Sever**; Ivo Pahole*; \\ Mirko Ficko*; Joze Balic* \& Igor Drstvensek* \\ *University of Maribor, Faculty of Mechanical Engineering, Smetanova ul. 17, 2000 Maribor, \\ Slovenia \\ ${ }^{* *}$ Faculty of mechanical engineering and naval architecture, Ivana Lučića 5, 10002 Zagreb, \\ Croatia \\ ***TECES, Research and Development centre of Electrical Machines, Pobreška cesta 20, \\ 2000 Maribor, Slovenia \\ E-mail: bogdan.valentan@uni-mb.si
}

\begin{abstract}
:
The investment casting of metal parts is a rapid tooling/manufacturing method for small series production, where wax pattern is produced separately and then extracted from the mould. The wax parts commonly used as patterns are usually obtained after wax casting silicone rubber moulds. The time needed for the wax to solidify is critical and difficult to predict. This article presents an experimental method for cooling-time determination using a simplified applicable solution (needed in hash industrial environment and short deadlines) based on real-life parts experience.
\end{abstract}

Key Words: Investment Casting, Wax Casting Silicone Rubber Moulds, Cooling Time, Rapid Manufacturing

\section{INTRODUCTION TO INVESTMENT CASTING}

Investment casting is a relatively old procedure (in ancient times artists used it for sculpture and jewellery) for metal parts production, which was reintroduced in its modern form after World War 2, and expanded greatly worldwide during the 1980's, in particular to meet growing demands for aircraft engines and plane structural parts. A pattern that can be burned out of mould is needed. Wax parts are commonly used for pattern production and can be produced using layered technologies (use of industrial waxes on modified stereolithography) especially suitable for complex parts or for wax casting into silicone rubber moulds for cost-effective serial production. Silicone Rubber Moulding (SRM) (Figure 1) is the fastest and cost-effective procedure for small series production. It can be considered as an indirect rapid prototyping/manufacturing procedure. It is especially suitable for simple-shaped parts and due to its silicone rubber characteristic (softness) for parts with outer dimensions from $1 \mathrm{~cm}$ up to $1 \mathrm{~m}$ in any direction as also presented by Tang et. al. (2007). As this will thus prevent mistakes in mould construction, some subsequent cutting and removing of silicone rubber is possible. SRM is commonly used for the castings of Polyurethanes, Wax, Low Melting Point Alloys, Medical implants and even in the food industry (Marzipan sweets).

\section{SILICONE RUBBER MOULDS AND WAX CASTING}

Silicone rubber is a polymer that has a 'backbone' of silicon-oxygen linkages. Two components - silicone rubber and catalyser are used in a case of mould production. The model must be equipped with a parting-plane, inlet channel, and degassing outlets. The model is positioned within a mould-making device. Parts made using layered technologies (rapid prototyping) can be used for the model. Both components of the silicone rubber 
(silicone and catalyst) are mixed in the correct proportions and aerated in a vacuumchamber. The model is then embedded in silicone; the liquid silicone rubber reacts with the catalyser and completely solidifies at $20^{\circ} \mathrm{C}$ in $24 \mathrm{~h}$. After vulcanization, the mould is cut at the parting-plane, and the pattern removed, as detailed on the web page of Rapiman (2011), where most of other rapid manufacturing techniques are also introduced.

In the case of polyurethane casting, there is a set curing time, so it is possible to exactly know when the part will become solid (polymerization finished). In the case of wax casting, there is no simple and accurate method for determining the solidification time. Damaged parts result if a mould is opened before the wax part becomes solid, (Figure 2) that, in some cases, can be repaired but more commonly need to be recast. Therefore, the time before the mould is opened is often unnecessarily prolonged, in order to ensure the wax part has completely solidified. In this manner, a lot of crucial time can be wasted, especially when considering Investment Casting as a rapid prototyping/manufacturing technology.

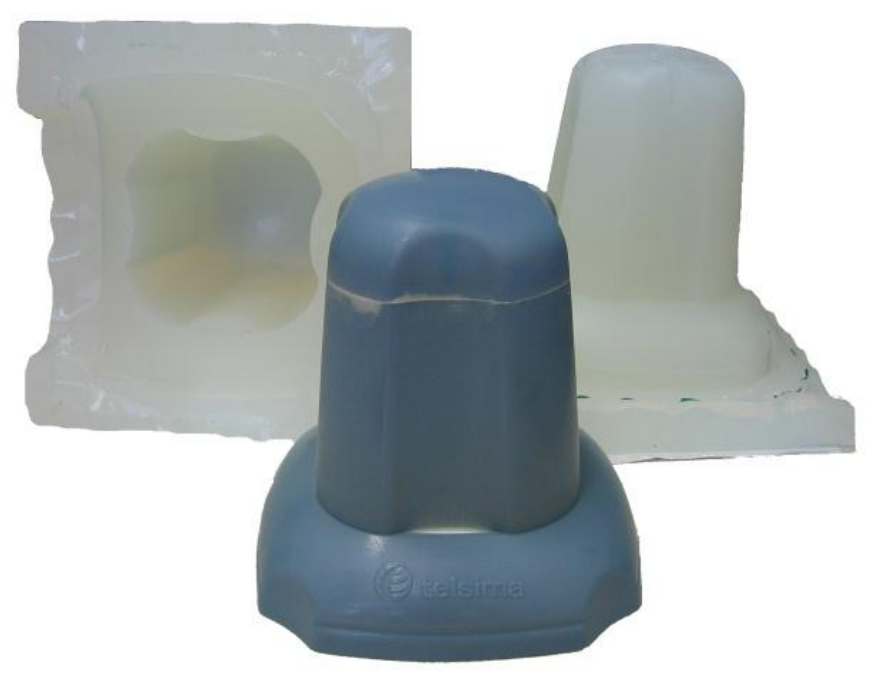

Figure 1: Silicone rubber mould with a pattern.

In order to determinate the time needed for wax part solidification, certain mould and part parameters found in thermodynamics need to be taken into consideration. There are several possible methods:

- One of commercially available software for casting simulations (Moldflow, Moldex, Cosmos/Flow or similar) being used. In this case, in order to obtain the proper material characteristics, certain parameters must be adjusted. Casting can then be simulated. This procedure can yield very good results, but it takes a lot of time to prepare the simulation, since the exact CAD model of our mould and proper parameter preparation are needed. Some advanced approaches were also established by Zhang et al. (2006).

- Use of simplified equations with experimentally determined parameters.

This paper presents those experiments needed for determining the time needed for wax parts to solidify, and the derivation of a simplified equation which enables calculation of the required cooling time from the basic mould and part parameters. Method can also be extended on more complex calculations with help of genetic programming (Brezocnik et al. 2004) or with introduction of some shape related parameters as described in preview work (Valentan et al. 2008, Cosic et al. 2010). 


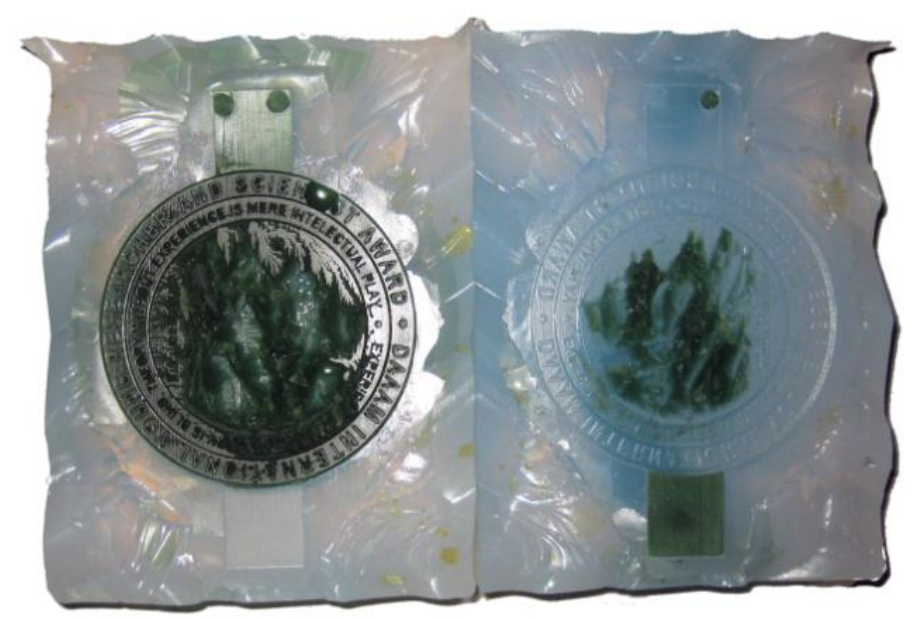

Figure 2: Damaged part as a result of still being in a liquefied state at the time of mould opening.

\section{SRM AND COOLING TIME}

Cooling time - the time period from casting until the mould can be opened, depends on several major parameters. Moulds usually need to be pre-heated, since wax needs slower cooling curves to obtain its shape. Cracks and too great material shrinkage are the most common defects caused by fast-cooling. The moulds used in this experiment were preheated to $70^{\circ} \mathrm{C}$. The wax used in our experiment was industrial wax from the MTT Technologies Group (2011), type WA-70, with a melting-point of $68-70^{\circ} \mathrm{C}$, and a casting temperature at $80^{\circ} \mathrm{C}$ (recommended casting temperature) as presented in Table I. Two environments were used for cooling - cooling at room temperature (this is not recommended by wax manufacturers since the wax cools too quickly), and cooling at $30^{\circ} \mathrm{C}$. Cooling-time is the time period from the end of casting until the temperature drops to $35^{\circ} \mathrm{C}$ at the wax part's core (independent of the tool's surrounding temperature).

Table I: Casting parameters.

\begin{tabular}{|l|l|l|}
\hline Parameter & Mark & Value \\
\hline Wax Casting temperature $\left({ }^{\circ} \mathrm{C}\right)$ & $T_{s w}$ & 80 \\
\hline Wax Ending temperature $\left({ }^{\circ} \mathrm{C}\right)$ & $T_{e w}$ & 35 \\
\hline Silicone starting temperature $\left({ }^{\circ} \mathrm{C}\right)$ & $T_{s s}$ & 70 \\
\hline
\end{tabular}

\section{TOOLS USED IN THE EXPERIMENT}

Three different moulds (Figure 3) were used for this experiment. A cubic tool was constructed especially for our experiment. We used a cubic shaped tool (mould) with a cubic shaped product (wax part). The cubic shape provides the most uniform heat distribution from the wax part through the SRM to the surface. The other two SRM's were randomly selected from the tool collection in our laboratory. The parameters for the tools and wax parts are given in Table II. 


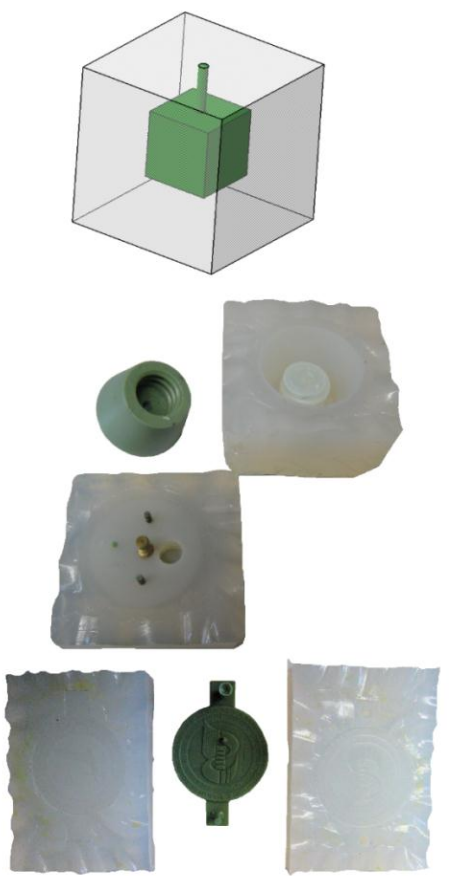

Figure 3: SRM parts; at the top - "cube", in the middle "cone" and "medal" at the bottom.

Table II: SRM and wax part parameters.

\begin{tabular}{|l|l|l|l|}
\hline ParameterlPart & Cube & Medal & Cone \\
\hline SRM Height $(m)$ & 0.1 & 0.05 & 0.110 \\
\hline SRM Width $(m)$ & 0.1 & 0.144 & 0.111 \\
\hline SRM Length $(m)$ & 0.1 & 0.109 & 0.086 \\
\hline SRM $d x^{*}(m)$ & 0.05 & 0.0505 & 0.051167 \\
\hline Wax part volume $V_{w}\left(\mathrm{~m}^{3}\right)$ & 0.000074901094 & 0.00002925087 & 0.000096021631 \\
\hline Wax part mass $m_{w}(\mathrm{~kg})$ & 0.056 & 0.0266 & 0.080 \\
\hline Wax part area $A_{w}\left(m^{2}\right)$ & 0.011129492 & 0.017498333 & 0.018999327 \\
\hline SRM mass $m_{s}(\mathrm{~kg})$ & 1.126 & 0.8 & 1.082 \\
\hline SRM external area $A_{s}\left(m^{2}\right)$ & 0.06 & 0.056692 & 0.062432 \\
\hline SRM volume $V_{s}\left(m^{3}\right)$ & 0.001 & 0.0007848 & 0.00105006 \\
\hline
\end{tabular}

${ }^{*} \mathrm{dx}$ is the average length from the SRM's centre to the nearest point on SRM surface

The wax and Silicone rubber parameters are presented in the producers' material data sheets (Table III).

Table III: Wax MTT WA-70 and silicone MTT VTV 800 parameters.

\begin{tabular}{|l|l|l|}
\hline Parameter & Mark & Value \\
\hline Wax Specific heat $(\mathrm{J} / \mathrm{KgK})$ & $C_{p w}$ & 2300 \\
\hline Wax Heat of Fusion $(\mathrm{J} / \mathrm{kg})$ & $Q_{s w}$ & 160 \\
\hline Silicone specific heat $(\mathrm{J} / \mathrm{KgK})$ & $C_{p s}$ & 1300 \\
\hline
\end{tabular}

\section{MEASURING AND CASTING EQUIPMENT}

Temperature measurements were taken using Metrix M-4560A digital multi-metre (Figure 4) equipped with a type $\mathrm{K}$ thermo coupling. This thermo coupling has a class 1 tolerance of \pm 1.5 between $-40^{\circ} \mathrm{C}$ and $375^{\circ} \mathrm{C}$ (Wikipedia, 2011). Measuring accuracy was previously checked using an ice-water mixture $\left(0^{\circ} \mathrm{C}\right)$ and boiling water $\left(100^{\circ} \mathrm{C}\right)$ to obtain the maximal possible 
accuracy for the measurements. The wax was cast in a MCP 4/01 Vacuum-chamber equipped with a wax heater. The vacuum-chamber is capable of absolute pressure down to $5 \mathrm{mbar}$, where the wax is cast to prevent a non-homogeny structure caused by the remaining air or water steam. An oven was used to cool-down the mould within a controlled environment, at preset temperature of $30^{\circ} \mathrm{C}$ (tolerance $\pm 1^{\circ} \mathrm{C}$ ). A TFD 128 temperature and air moisture data logger was used to ensure control of the tool's surrounding air. The TFD 128 has a temperature-measuring area of $-20^{\circ} \mathrm{C}$ to $+80^{\circ} \mathrm{C}$, with tolerance of $0.1^{\circ} \mathrm{C} / \pm 0.8^{\circ} \mathrm{C}(\mathrm{ELV}$, 2011).

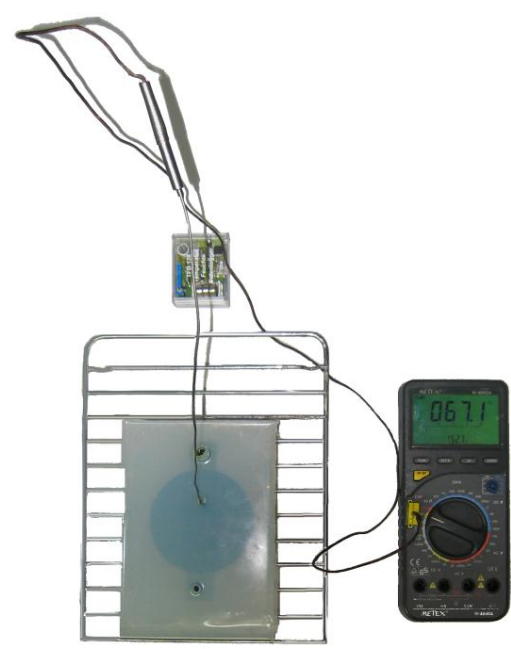

Figure 4: Measuring with METEX M-4560A digital multi-metre used for temperature measurements. The multi-metre measures the current temperature, so measurements over known time intervals were needed. A data logger should be used to simplify data acquisition.

\section{THERMODYNAMICS}

Thermodynamics is a highly complex science where use of complex mathematic is practically indispensable Zivic et al. (2010). Wax-cooling inside an SRM is a complex process. These parameters and processes should be taken into consideration in order to determine the exact time needed for wax-cooling:

- Wax part's heat capacity

- Wax part's thermal conductivity

- Wax part's fusion heat

- Specific heat of melted wax

- Silicone tool's heat capacity

- Silicone tool's thermal conductivity

- Silicone tool's fusion heat

- Heat transfer (conduction) wax-silicone

- Heat transfer (conduction) silicone surrounding air

- Heat transfer (conduction) in air space, originating from wax shrinkage in the space between the wax part and the silicone tool

- Heat capacity of the air originating in the space between the wax and silicone

- Heating of surrounding air for Silicone-Wax -Air heat conduction

- Shape complexity of wax part or even the silicone rubber tool that causes uneven heat distribution

- SRM heating as a result of heat transfer from wax to SRM

In order to obtain a more user-friendly end-result (we need keep in mind, that result shod be useful for worker in casting plant), only a few of those processes are taken into consideration. 


\subsection{Joint quantity of heat $-Q$}

The joint quantity of heat from the wax part and silicone rubber mould is a heat quantity caused by temperature change and fusion heat.

The temperature change for wax is, in our case, from $80^{\circ} \mathrm{C}$ to $35^{\circ} \mathrm{C}$ :

$$
\Delta T_{w}=T_{s w}-T_{e w}=80^{\circ} \mathrm{C}-35^{\circ} \mathrm{C}=45^{\circ} \mathrm{C}
$$

So heat $Q$ of the wax, where mw is the wax mass, Cpw specific heat capacity of the wax, and $\Delta T w$ wax temperature change, regarding fusion heat $\mathrm{Q} \Delta$ is:

$$
Q_{w a x}=Q_{\Delta t w}+Q \Delta=m_{w} C_{p w} \Delta T_{w}+m_{w} \cdot 160\left\lfloor\frac{J}{k g}\right\rfloor
$$

The temperature change for SRM is, in our case, from $70^{\circ} \mathrm{C}$ to $35^{\circ} \mathrm{C}$ :

$$
\Delta T_{s}=T_{s s}-T_{e s}=70^{\circ} \mathrm{C}-35^{\circ} \mathrm{C}=35^{\circ} \mathrm{C}
$$

so heat $Q$ of SRM where ms is SRM mass, Cp's specific heat capacity of SRM, and $\Delta T$ 's SRM temperature change is:

$$
Q_{\text {silicone }}=m_{s} C_{p s} \Delta T_{s}
$$

The joint-heat quantity is the total of the wax and the SRM heat:

$$
Q=Q_{\text {wax }}+Q_{\text {silicone }}
$$

$Q$ is the joint quantity of heat needed to carry-out of the system in order to cool down the wax part to $35^{\circ} \mathrm{C}$. Heat is delivered by conduction since the wax is stationary in a tool after the casting procedure is finished. The temperature of the surrounding air is constant (or we presume it is, in our case). The heat quantities for the tested parts are written in Table IV.

Table IV: Joint-heat quantities of tested parts.

\begin{tabular}{|l|l|l|l|}
\hline ParameterlPart & Cube & Medal & Cone \\
\hline$Q_{\text {wax }}(\mathcal{J})$ & $5,804.96$ & $2,757.36$ & $8,292.8$ \\
\hline$Q_{\text {silicone }}(\mathcal{J})$ & $51,233.0$ & $36,400.0$ & $49,231.0$ \\
\hline$Q(J)^{*}$ & $57,037.96$ & $39,157.36$ & $57,523.8$ \\
\hline
\end{tabular}

\subsection{Thermal energy transfer by time}

A simpler equation was used in order to solve our problem and obtain a simplified but still accurate equation for cooling-time determination:

$$
\frac{\Delta Q}{\Delta t}=-K \cdot A \cdot \frac{\Delta T}{\Delta x} \Rightarrow \Delta t=\frac{Q}{K \cdot A \cdot\left(\frac{\Delta T}{\Delta x}\right)}
$$

Because of simplification, as mentioned above, and certain unknown parameters (material and geometrical parameters), parameter $K$ cannot be determined and, consequently, the exact time cannot either. Therefore an approximation is needed: 


$$
K \Rightarrow k_{B}
$$

where parameter $k_{B}$ is experimentally-set. $k_{B}$ is set by measuring the cooling-times of the tested systems and represents unknown parameters. Despite most of the unknown parameters being non-linearly dependent, with this approximation certain mistakes are entered, but within the borders of expected accuracy which in our case, are around $\pm 5 \%$.

A simplified average-temperature change of our system (SRM and wax) was used for cooling-time determination, using Equation 6:

$$
\begin{aligned}
& \Delta T_{21^{\circ} \mathrm{C}}=\frac{T_{s w}+T_{s s}}{2}-T_{E}=\frac{80^{\circ} \mathrm{C}+70^{\circ} \mathrm{C}}{2}-21^{\circ} \mathrm{C}=54^{\circ} \mathrm{C} \\
& \Delta T_{31^{\circ} \mathrm{C}}=\frac{T_{s w}+T_{s s}}{2}-T_{E}=\frac{80^{\circ} \mathrm{C}+70^{\circ} \mathrm{C}}{2}-31^{\circ} \mathrm{C}=44^{\circ} \mathrm{C}
\end{aligned}
$$

Where $T_{s w}$ is the starting temperature of the wax, $T_{s s}$ is the starting temperature of the SRM, and TE is the environmental temperature of the air surrounding the SRM.

Therefore, the searched cooling time $t$ is:

$$
t=\frac{Q}{k_{B} \cdot A_{S} \cdot\left(\frac{\Delta T}{\Delta x}\right)}
$$

where the parameters represent:

$t$ - Cooling time of wax part,

$Q$ - Joined heat energy of SRM, and the wax part,

$k_{B}$ - Impacted thermal deviation correction factor,

$A_{S}-$ SRM's external area,

$\Delta T$ - Average temperature change of our system,

$\Delta x$ - Average length from the SRM's centre to the nearest surface (equal to the presented $d x$ ).

\section{COOLING TIMES OF TESTED PARTS}

Figures 5 and 6 presents cooling curves for our test parts at different surrounding temperatures. It can be seen, the shapes of the cooling curves are generally similar the deviation at the beginning is caused by manual temperature measurements, but since only the end time is needed (end of each cooling curve) no error is made by this.

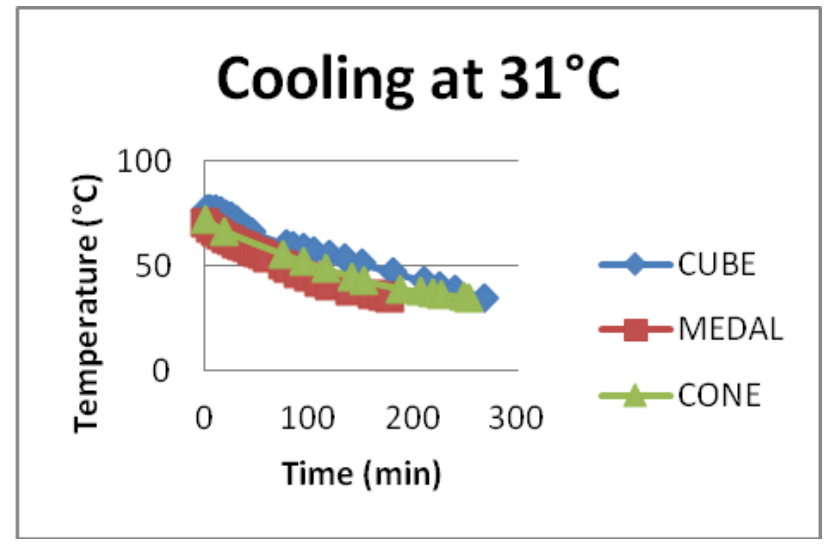

Figure 5: Cooling curves of selected parts cooling down at $31^{\circ} \mathrm{C}$. 


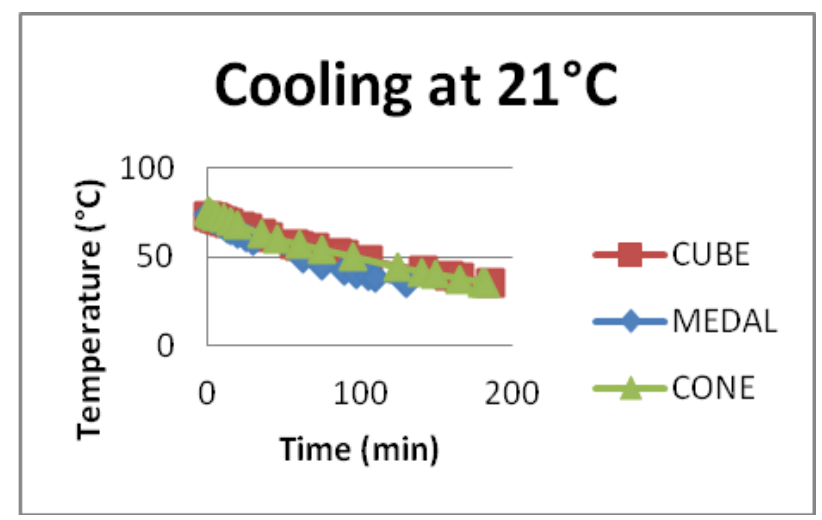

Figure 6: Cooling curves of selected parts cooling down at room temperature of $21^{\circ} \mathrm{C}$.

Our cooling-times factor $k_{B}$ was calculated backwards with the help of Equation 11:

$$
k_{B}=\frac{Q}{t \cdot A_{S} \cdot\left(\frac{\Delta T}{\Delta x}\right)}
$$

where the parameters represents:

$t$-Cooling-times of the wax parts,

$Q$ - Joined heat energy of SRM and the wax part,

$A_{S}$ - SRM's external area,

$\Delta T$ - Average temperature change of our system,

$\Delta x$ - Average length to the SRM surface from the SRM's centre to the nearest surface.

It is important to state, that factor $\mathrm{kb}$ is temperature-dependent, as seen from the average values $k_{b 21}$ and $k_{b 31}$, so if some other cooling temperature were to be used, factor kb should be calculated again, otherwise the calculated error is bigger than the estimated. The calculated parameters for all the tested parts are shown in Table V.

Table V: calculated parameters kB21 and kB31 for the tested parts.

\begin{tabular}{|l|l|l|}
\hline & $k_{B 21}$ & $k_{B 31}$ \\
\hline CUBE & 0.078872351 & 0.067181 \\
\hline MEDAL & 0.082812252 & 0.074227 \\
\hline CONE & 0.079948634 & 0.070306 \\
\hline
\end{tabular}

For common use, the average values $\left(k_{B 21}\right.$ and $k_{B 31}$; index 21 and 31 representing the surrounding temperatures) are calculated:

$$
\begin{aligned}
& k_{B 21}=0.08054 \\
& k_{B 31}=0.07057
\end{aligned}
$$

A simplified equation for the cooling-time determination at the usual (and required by the wax producer) cooling temperature of $31^{\circ} \mathrm{C}$ is:

$$
t=\frac{Q}{0.07057 \cdot A_{S} \cdot\left(\frac{\Delta T}{\Delta x}\right)}
$$


Fast cooling-time determination can be made by Excel form (or some other multiple parameters' memory calculator).

\section{CONCLUSIONS}

Production time is now-days more important than ever before (Opetuk et al., 2008). The key factor in the investment casting process, as also in indirect rapid manufacturing/tooling procedures, is a wax core that should be undamaged and completely uniform. Also, for a continuous production, the wax parts should be manufactured as quickly as possible. Cooling-time can be difficult to predict when based only on experience, and since commercially available software's are too expensive and exact calculation with all laws of thermodynamics taken into consideration, too much time-consuming, this leads to relatively large amounts of unsuitable wax parts. The presented solution enables fast production of wax parts from silicone rubber moulds.

Equation 10 with parameters $k_{B 21}$ (cooling at $21^{\circ} \mathrm{C}$ ) and $k_{B 31}$ (cooling at $31^{\circ} \mathrm{C}$ ) is the answer to our original question, as when a specific mould can be safely opened and finished wax parts obtained. An accuracy of $\pm 5 \%$ can be achieved using the presented solution. In order to be on the safe side, $5 \%$ should always be added to the calculated time.

Since end of 2009 on Faculty of Mechanical Engineering in Maribor cooling times for all wax products made with SRM are calculated with presented method and since then the efficiency has raised dramatically.

\section{REFERENCES}

[1] Brezocnik M, Kovacic M, Ficko M. (2004). Prediction of surface roughness with genetic programming, Journal of materials processing technology Volume: 157 Special Issue: Sp. Iss. SI Pages: 28-36

[2] Cosic P, Babic A, Antolic D. (2010). Process Selection, Sequence of Operations and Shape Complexity - Criteria for Process Improvement, Strojarstvo Volume: 52 Issue: 1 Pages: 515

[3] ELV: Temperatur-Feuchte Datenlogger TFD 128 Bedinungsanleitung, ELV Elektronik AG, PF 1000,http://www.elv-

downloads.de/Assets/Produkte/6/660/66071/Downloads/tfd128_um_g_060523.pdf, acceset 13. 12. 2011

[4] MTT: http://www.mtt-group.com/index.html - Data sheets of wax and silicone rubber used in experiment; accessed 18. 09. 2011

[5] Opetuk T, Cosic P. (2008). The application of group technology for the production time estimation, Annals of DAAAM for 2008 \& Proceedings of the 19th international DAAAM symposium - Intelligent manufacturing \& automation: Focus on next generation of intelligent systems and solutions book series: Annals of DAAAM and proceedings, Pages: 991-992

[6] Rapiman: http://www.rapiman.net/index.php?pid=26\&sid=27\&mid=8; Web-page of Rapid Prototyping and Innovative Manufacturing Network; accessed 12. 09. 2011

[7] Tang Y, Tan WK, Fuh JYH et al. (2007). Micro-mould fabrication for a micro-gear via vacuum casting, Journal of materials processing technology Volume: 192 Special Issue: Sp. Iss. SI Pages: 334-339

[8] Valentan, B., Brajlih, T., Drstvensek, I., Balic, J. (2008). Basic solutions on shape complexity evaluation of STL data. J. Achiev. Mater. Manuf. Eng., vol. 26, iss. 1, Pages. 73-80. http://157.158.19.167/papers_vol26_1/2619.pdf

[9] Zhang XP, Xiong SM, Xu QY. 82006). Numerical methods to improve the computational efficiency of solidification simulation for the investment casting process, Journal of materials processing technology Volume: 173 Issue: 1 Pages: 70-74

[10] Zivic M, Galovic A, Ferdelji N. (2010). Local entropy generation during steady heat conduction through a plane wall, Tehnicki vjesnik-Technical gazette, Volume: 17 Issue: 3 Pages: 337341

[11] Wikipedia: http://en.wikipedia.org/wiki/Thermocouple - Thermocouples properties and classification; accessed 12. 09. 2011 